\title{
Cognition Clock Test
}

National Cancer Institute

\section{Source}

National Cancer Institute. Cognition Clock Test. NCI Thesaurus. Code C157012.

A test of the ability of an individual to accurately place the numbers and hands of a clock

in their usual and specified positions. 